MATEC Web of Conferences 53, 01009 (2016)

DOI: $10.1051 /$ matecconf/20165301009

(C) Owned by the authors, published by EDP Sciences, 2016

\title{
Stress-Strain State of Brick Masonry Vault with an Aperture
}

\author{
Vladimir Bespalov ${ }^{1, a}$, Romuald Orlovich ${ }^{2}$ and Sergey Zimin ${ }^{1}$ \\ ${ }^{1}$ Peter the Great Saint-Petersburg Polytechnic University, 29 Polytechnicheskaya st., St.Petersburg, 195251, \\ Russian Federation \\ ${ }^{2}$ West Pomeranian University of Technology Szczecin, al. Piastów 17, Szczecin, 70-310, Poland
}

\begin{abstract}
A study of the mechanical behavior of brick masonry vaults with cut aperture is presented. The vault in New Holland complex in St. Petersburg was assumed as an illustrative example. This vault was tested and simulated in order to evaluate its stress-strain state. Comparison of the results of numerical analysis and experimental test data has been performed. The optimal way to perform an aperture was defined: aperture should be cutting parallel to the lines of action of the principal stresses minimizing direction transversal to these lines. As a further development of the research, the investigation of the various types of aperture in vaults has been recommended to perform using different simulating models and methods.
\end{abstract}

\section{Introduction}

It frequently needs to adapt historical buildings to modern requirements during the restoration process. Such adaptation usually includes applying modern materials, structural changes in certain building elements and the installation of new systems - air ducts, water-supply facilities, elevators etc. Existent apertures are often inadequate for these systems and it requires to cutting-out additional units. As a consequence, significant changes in stress state and analytical model of structures are taking place. Since the historical buildings are built mainly of stone and brick masonry, its analysis is the most difficult, especially analysis of brick masonry vaults.

Simulation and analysis of brick masonry perform either by masonry continuum model [1-4] or by discrete model $[5,6,7]$. The continuum model is mainly used for the analysis of the stress state of massive masonry structures. Otherwise, the discrete model is applicable for studying the crack propagation phenomena, interaction between brick and mortar under load and simulating tests of masonry samples. In addition, there are intermediate models, combining the first two $[8,9,10]$.

Masonry vaults simulation is a more complex task. The review of manuscripts recently performed [11] demonstrate the lack of Russian works devoted to this subject. Foreign investigations can be divided into two groups. The first one is devoted to searching for numerical simulation techniques allowing the behavior of vaults in different configuration to be the most correct [12-15]. The second one is experimental study of brick arches and vaults failure phenomena [16-19]. Studies describe in detail the sources of the vaults failure, loss of stability and theirs development. However, these studies consider ordinary and unmodified arches and vaults. While behavior of vaults, which contain variety of additional apertures, and ways of their stresses redistribution is of practical concern.

\footnotetext{
${ }^{\mathrm{a}}$ Corresponding author : chanchullero@yandex.ru
} 
Authors had tested the vault of restored Forge building in New Holland complex located in St. Petersburg. During the restoration, a need arose for a large aperture in one of vaults to bring out the air duct. After cutting the aperture, strains were measured on adjacent areas during the removing of arch falsehood. Besides, the vault was simulated in ABAQUS software to evaluate its stress state. The results of experimental tests and numerical analysis are presented in the paper.

\section{Initial data and task description}

It was necessary to complete the following tasks to define the aperture influence on the stress-strain state of the vault:

- to measure the strain on the adjacent areas to the aperture of the existent vault;

- to simulate and analyze this vault in ABAQUS software;

- to compare the measurement results and the data of numerical simulation.

a)

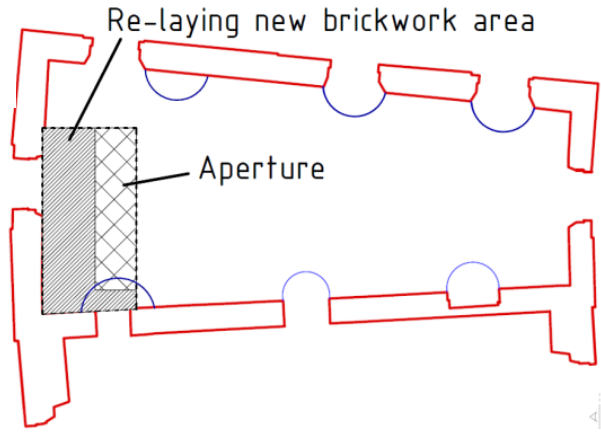

b)

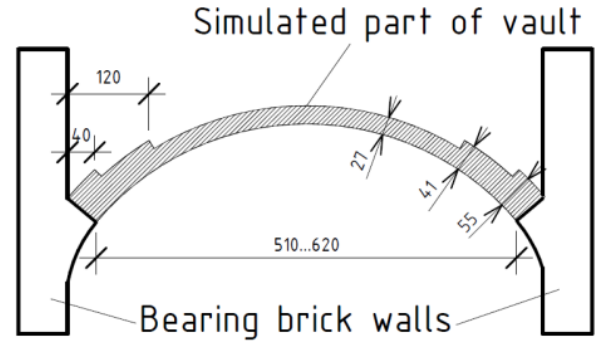

Figure 1. (a) Vaulted ceiling plan including spandrels, aperture and re-laying area; (b) The structural scheme of vault, dimensions in $\mathrm{cm}$.

An aperture was cut out from the vault of Forge building. An aperture has dimensions of about $88 \times 422 \mathrm{~cm}$. For that scope, old brickwork has been removed from wide area of vault and the new has been laid out (Fig. 1, a). Vault is cylindrical with variable radius and additional cross-section thickness on abutments (Fig. 1, b). The brickwork has following main features: volume weight $\gamma=1800 \mathrm{~kg} / \mathrm{m} 3$, modulus of elasticity E= $1680 \mathrm{MPa}$, Poisson's ratio $\mu=0.2$.

\section{Experimental tests}

External surface of the vault was the most applicable to measurements. The strains were measured by dial gauges installed on one arc of vault in proximity to the aperture at three points (Fig. 2). Dial gauge supports were anchored in the bricks in such a way as to the reference indicator base was in each case about $20 \mathrm{~cm}$.

Measurements were taken during wedges easing. At that moment, vault begins to take up the dead load. The first measurement check was made before wedge easing process had started. The second measurement check was taken when all the wedges were stroke out and the vault was settled in the operational position. Further measurements were not carried out, therefore, only the elastic strains have been taken into account, without creep strains. 


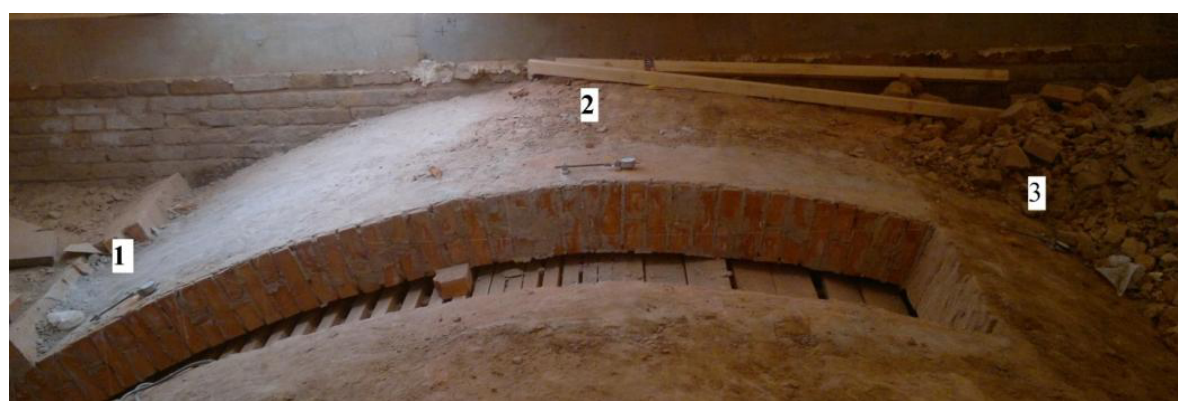

Figure 2. Location of the dial gauges on the target vault.

The accuracy of indicators was about $0.001 \mathrm{~mm}$. The strains were defined under results of measurements: the first point $(-0.007) \mathrm{mm}$, second point $(-0.004) \mathrm{mm}$, third point $(-0.013) \mathrm{mm}$. Indications of the third indicator allows to deduce that the new-laying brickwork (areas 1 and 2) is more rigid. The corresponding relative strains to the $20 \mathrm{~cm}$ reference base: the first area $3.5 \cdot 10-5$; second 2.10-5; the third 6.5 $10-5$. For adopted elastic modulus $1680 \mathrm{MPa}$ principal compressive stresses in these areas will be: $58.8 \mathrm{kPa}, 33.6 \mathrm{kPa}$ and $109.2 \mathrm{kPa}$, respectively.

\section{FE simulation}

By the structural scheme (Fig. 1, b) estimated on the base of [20] that the vertical support reaction and horizontal thrust of its dead load is transmitted to the foundation by its abutments directly on the bearing wall axis. In this case, most accurate results of the analysis would have been if simulated vault is slit transverse to its cross section at the point adjoining to the supporting wall.

Vault static analysis is performed using ABAQUS. The three-dimensional model was generated by volume finite elements. Connection between spandrel and vault was assumed as rigid fixing. The transmits of vertical and horizontal reaction forces from spandrels canopy to the adjacent wall were excluded. It was also assumed that the vault does not bear against the adjacent transversal brick walls. The analysis is performed from its dead load only with a partial safety factor of 1.1 . The analysis does not take into account the filling which is covering abutments because of its insignificant influence on the target area.

The vault was simulated at two phases - the initial state and the current state with cut aperture (Fig. 3 a, b).

a)

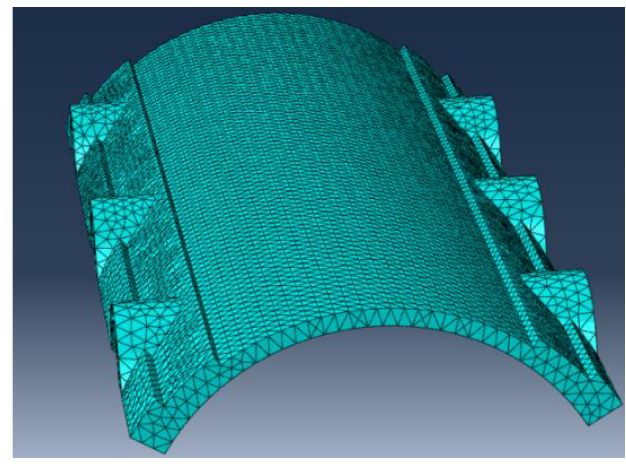

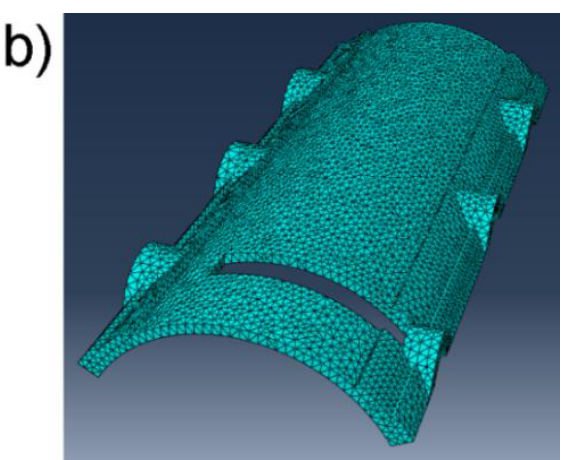

Figure 3. Finite-element models of vault. (a) the initial state, (b) a vault with a cut aperture.

Considered vault in the normal state has a critical area in the typical [21, 22] regions: minor tensile stresses are located in crowns of spandrels and concentration of compressive stresses at their abutments, and the stress concentration in the area of cross section differentials (Fig. 4, 5). 


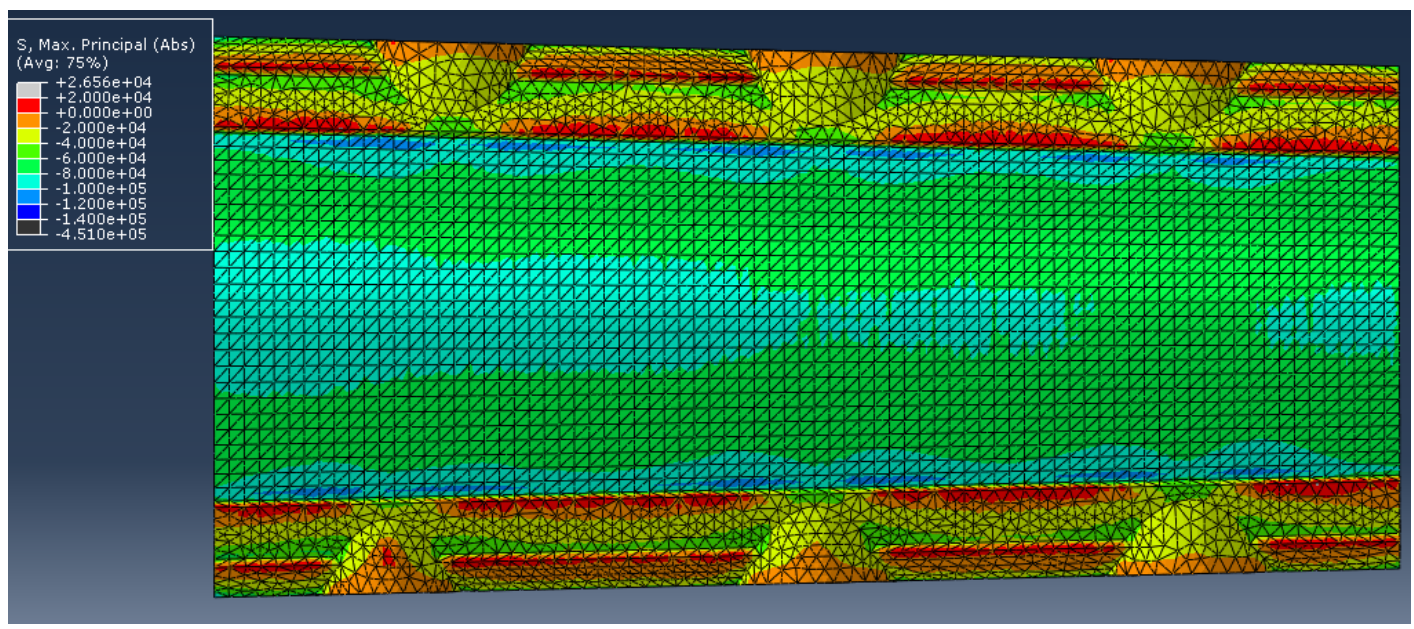

Figure 4. Maximum principal stresses on an external surface of the vault, $\mathrm{Pa}$.

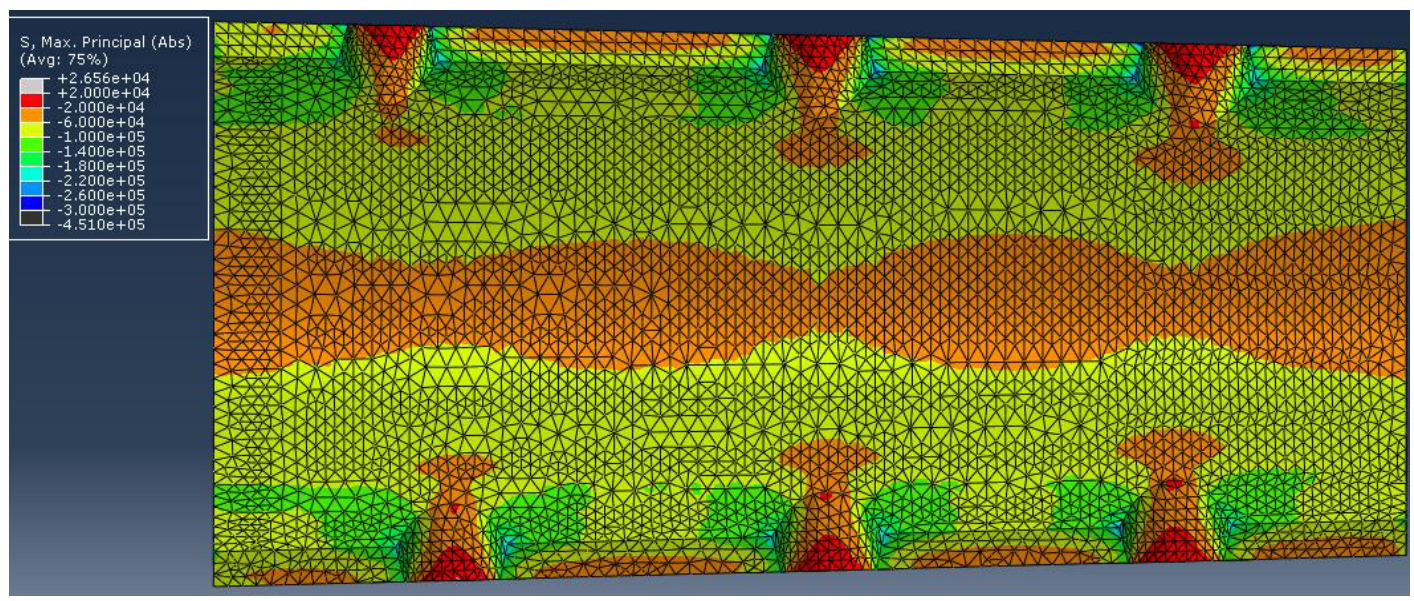

Figure 5. Maximum principal stresses on an internal surface of the vault, $\mathrm{Pa}$.

Critical areas rose on the border of the aperture after cutting it out (Fig. 6). A danger tensile stresses acting perpendicular to the main stream of the compressive stresses rose at the end of the opening (Fig. 7). On the contrary, the spandrel adjacent to the opening has become partially unloaded; tensile stresses on its crown has disappeared and the magnitude of compressive stresses in its abutments has decreased (Fig. 8).

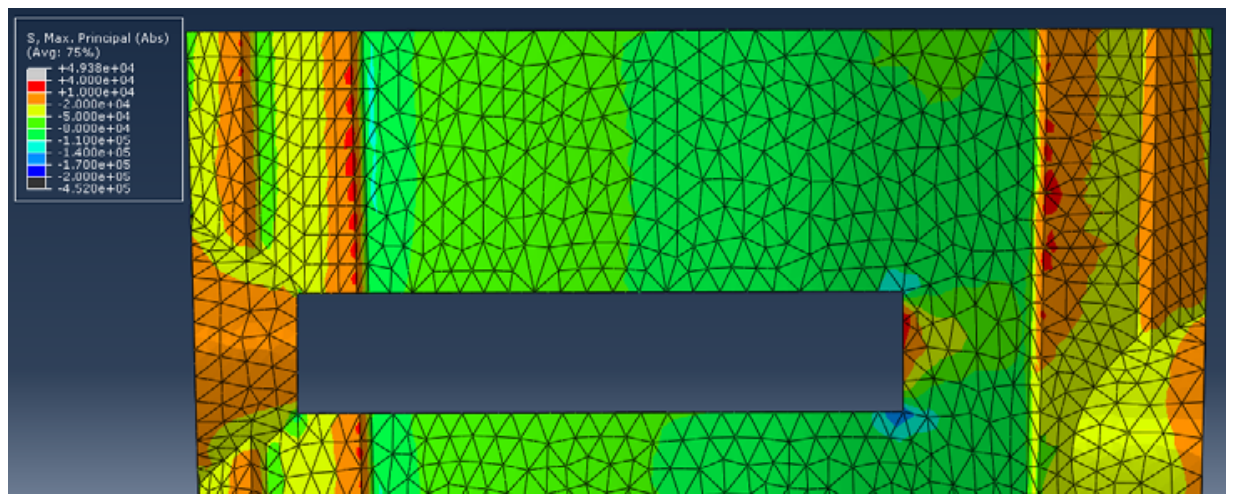

Figure 6. The maximum principal stresses in the apertures area at the external side, $\mathrm{Pa}$. 


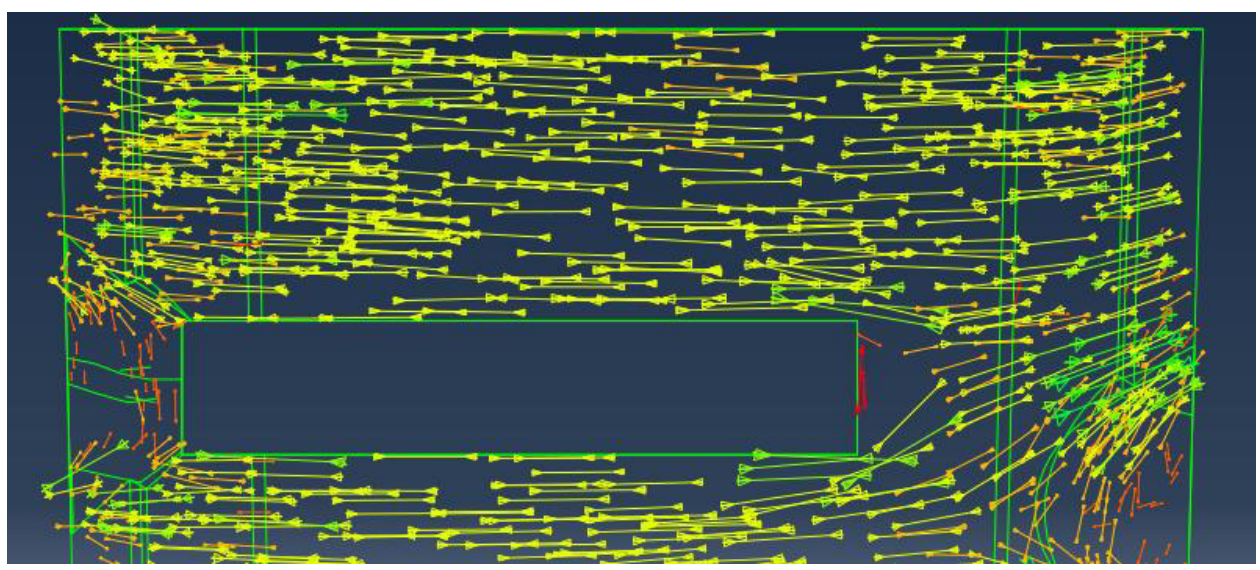

Figure 7. The paths of the maximum principal stress in the apertures area.

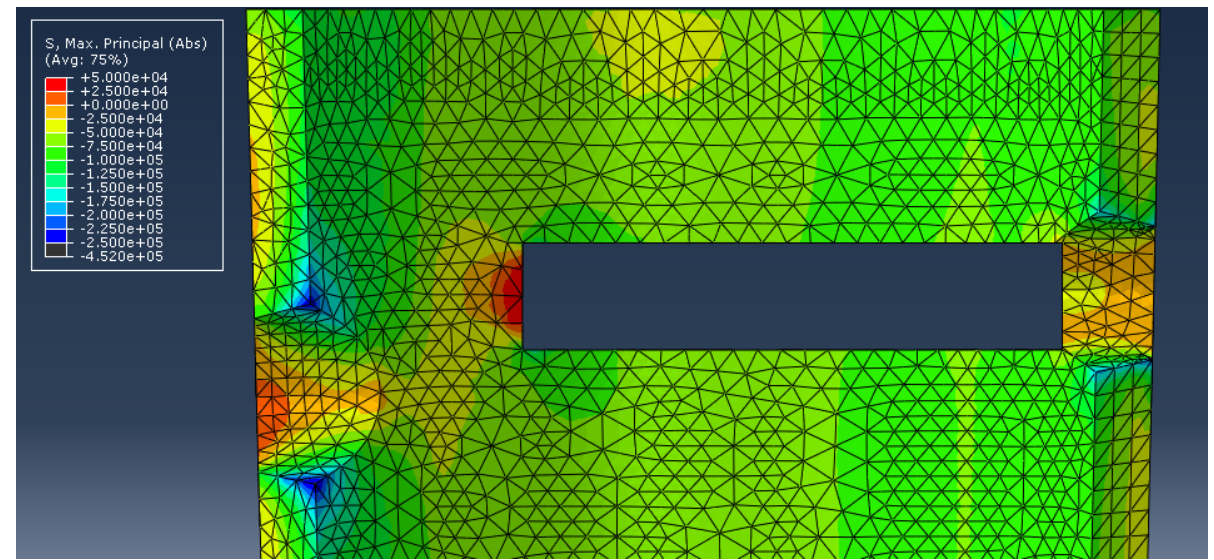

Figure 8. The maximum principal stresses in the apertures area at the internal side, Pa.

Compressive stresses are as follows: $1-(0.07 \ldots 0.08 \mathrm{MPa}), 2-(0.08 \ldots 0.09 \mathrm{MPa}), 3-(0.11 \ldots$ $0.12 \mathrm{MPa}$ ) at points corresponding to points of the vault considered in natural measurements. Thus, stresses in old brick masonry coincide numerically with the stresses in the analytical model. Inconsistency stresses in FE model to the stresses in re-laying brickwork were presumably caused by the greater stiffness of the masonry in that area.

\section{Conclusions}

Evaluation of the paths of the maximum principal stresses allows to conclude that the aperture preferably cut parallel to the lines of action of the principal stresses. On the other hand, the aperture performing in a direction transversal to these lines causes dangerous tensile stress.

Comparison of the results of numerical analysis and experimental test data showed the permissibility of using masonry continuum model in a numerical analysis of the vault. The discrepancy of results at the new masonry was caused by its greater stiffness, as characteristics were given from the old brick masonry in the simulation for the entire vault.

The aperture performing in the vaults should make strength analysis based on numerical simulation as a prediction in the context of a minor knowledge about the behavior of masonry vaults, as well as a variety of their structural version. 
As a further development of the research, the investigation of the various types of aperture in vaults is highly recommended to perform using different simulating models and methods.

\section{References}

1. M. Como, Meccanica, 27, 185-194 (1992)

2. O.A. Kamal, G.A. Hamdy, T.S. El-Salakawy, HBRC J., 10, 235-246 (2014)

3. S. Galassi, M. Paradiso, G. Tempesta, Open J. of Civ. Eng., 3, 18-26 (2013)

4. G. Creazza, R. Matteazzi, A. Saetta, R. Vitaliani, J. of Str. Eng., 128, 646-654 (2002)

5. S. Galassi, M. Paradiso, IERI Proc., 7, $62-70$ (2014)

6. S. Di Pasquale, Meccanica, 27, 173-184 (1992)

7. I.E. Demchuk, A.V. Halaliuk, Proc. of the BSTU, 1, 122-128 (2013)

8. S.S. Zimin, V.V. Bespalov, A.S. Kazimirova, Proc. of the DonNACEA, 3, 33-37 (2015)

9. M. Gilbert, C. Melbourne, The Str. Eng., 72, 356-361 (1994)

10. A. Penna, S. Lagomarsino, A. Galasco, Earthquake Eng. Str. Dyn., 43, 159-179 (2014)

11. S.S. Zimin, O.D. Kokotkova, V.V. Bespalov, CUBS, 2, 57-72 (2015)

12. E. Rizzi, F. Rusconia, G. Cocchettia, Eng. Str., 60, 241-257 (2014)

13. G. Milani, A. Tralli, IJSS, 49, 808-834 (2012)

14. G. Milani, Adv. in Eng. Software, 79, 91-110 (2014)

15. P. Block, L. Lachauer, MRC, 56, 53-60 (2014)

16. C. Melbourne, M. Gilbert, M. Wagstaff, The Str. Eng., 75, 297-305 (1997)

17. L. Anania, G. D'Agata, C. Giaquinta, A. Badala, APCBEE Proc., 9, 401-406 (2014)

18. J. Witzany, T. Cejka, R. Zigler, Proc. Eng., 14, 2086-2093 (2011)

19. V. Sarhosis, S.W. Garrity, Y. Sheng, Eng. Str., 88, 1-11 (2015)

20. R. Ahnert, Typische Baukonstruktionen von 1860 bis 1960 zur Beurteilung der vorhandenen Bausubstanz (Verlag für Bauwesen, Berlin, 1991)

21. P. Block, L. Lachauer, IJAH, 8, 312-335 (2014)

22. A. Tralli, C. Alessandri, G. Milani, The Open Civ. Eng. J., 8, 272-287 (2014) 